\title{
Priority of strategic plans in BSC model by using of group decision making model
}

\begin{abstract}
Strategic planning is especially important for organization's success and creation of competitive advantage in a competitive and complicated environment, and on the other hand achievement and implementation of strategies can perform an important role for the purpose of organizations' success, balanced scorecard is a new tool for designing operational strategies. One of Balanced Scorecard problems is the abs use of priority in strategic plans' performance. So, in this article by using proposed model, using the consensus of organization's managers and experts' opinions, measures of four perspectives and general objectives are determined in BSC, and then using experts' opinions and taking the relative importance of decision makers' opinions into consideration, by using 1Topsis method that it is one of Group Decision Making Model, the performances of strategic plans are prioritized in BSC model. The introduced method is used in a study and extracted results from it are analyzed from different points of view. In this article Initiatives is called strategic plans.
\end{abstract}

Keyword: Strategic planning; Balanced scorecard model; Multiple attribute decision making (MADM); Group decision making; TOPSIS 